J. Lake Sci.(湖泊科学), 2008, 20(3): 396-402

http://www.jlakes.org. E-mail: jlakes@niglas.ac.cn

(C)2008 by Journal of Lake Sciences

\title{
厚德载物 桃李天下
}

\section{“地理环境变化研究”学术研讨暨施雅风院士九十华诞座谈会在南京举行}

【编者按】 2008 年 3 月 21 日是我国著名的自然地理学家施雅风院士九十华诞. 3 月 20 日, “地理环境变 化研究”学术研讨暨施雅风院士九十华诞座谈会在中国科学院南京地理与湖泊研究所隆重举行. 应邀出 席座谈会的为在宁部分与施老有长期科研合作关系的著名学者，包括赵其国院士、王颖院士、朱大奎教 授、王富葆教授、朱诚教授、徐琪研究员、唐领余研究员、王建教授、张忍顺教授、李世杰研究员、屠 清瑛研究员、余之祥研究员、沈道齐研究员、王苏民研究员、朱季文研究员、季子修研究员、陈家其研 究员等老同志，以及施老在南京培养的部分学生等 30 多人.中共中央政治局委员、书记处书记、中央组 织部部长李源潮同志专程发来亲笔书写的生日贺卡; 中国科学院地学部办公室专门打来电话祝贺.

施雅风院士 1944 年浙江大学研究生毕业后, 即进入中国地理研究所工作. 1949 年后, 历任中国科学 院地理研究所助理研究员、副研究员. 1958 年以后组织祁连山等西北冰川考察, 发起冻土与泥石流研究, 创建中国科学院兰州冰川冻土研究所, 任研究员、所长与名誉所长. 1985 年起, 兼任中国科学院南京地理 与湖泊研究所研究员. 1980 年当选为中国科学院学部委员、地学部副主任. 曾兼任中国地理学会理事长. 主编专著 16 部，发表论文 200 多篇，成果先后获得国家自然科学一等奖、三等奖和国家科技进步二等奖. 2006 年获得甘肃省科技功臣称号.

施老是一位长期奋斗在科研一线的科学工作者, 是一位不断创新的科学领导者, 是一位充满激情和奉献 精神的老革命工作者; 他为中国科学院南京地理与湖泊研究所前身中国地理研究所的建立作出了重要贡献, 是 中国知识分子一个时代的杰出代表. 他所体现出的无私奉献、不断创新、勤恳工作的精神, 他对学科发展和科研 工作的高瞻远瞩、严谨的治学态度、对人才培养和科研团队建设的远见卓识, 都是我们学习的榜样和楷模.

以下是当日座谈会的主要发言的详细纪要. 兹汇编如下, 以赐读者. 祝先生健康长寿!

杨所长: 尊敬的施老，师母，还有尊敬的赵院士，王院士，各位老师，各位师兄师弟，今天下午我们在这 召开一个小规模但很有意义的座谈会.今天特邀的嘉宾都是近 20 年，有的可能更长时间和施老有密切科 研联系的老同事、老朋友，我们欢聚一堂，共同祝贺施老 90 华诞. 3 月 21 日是施老 90 寿辰，施老 1919 年出生, 1937 年考人到浙江大学史地系, 1947 年在南京秘密加人共产党. 1949 年起一直在科学院地理所工 作, 1958 年到兰州组织领导西部冰川考察, 同时组建兰州冰川冻土研究所, 1980 年当选为学部委员. 曾兼 任中国地理学会的理事长, 国际冻土学会、冰川学会的理事, 英国皇家地质学会、国际第四纪学会等名 誉会员. 施老作为一位享誉国内外的地学大师, 为我国冰川冻土科学的创立和发展以及地理环境变化研 究作出了杰出的贡献. 我们今天欢聚一堂, 以简朴而热烈的方式为他老人家祝寿, 也希望通过这个座谈 会学习施老, 能秉承他母校浙大的求是精神、正派为人、淡泊名利以及爱党爱国的高尚情操. 施老让我 们学习的东西很多, 尤其令人敬佩的是施老对科学的毕生追求, 今天在座的实际上都是施老在古稀之年 以后科研工作中接触的同志，大家都深深为施老的执着精神所感动.

施雅风: 今天的会开得很隆重, 我真是不敢当. 我先来讲一讲地理所, 我们的南京地理所. 从墙上挂的这 些照片来看, 地理所最早是 1940 年在重庆北碚开始创建, 我有幸在 1944 年进人其中, 当时地理所有 40 多人. 地理所的老人, 除了我本人以外, 现在就剩下南大的郭令智院士，还有广州地理所的钟功甫研究 员，在美国的谢觉民教授. 地理所从重庆迁到南京，解放后就由中国科学院接管了，当时只剩下 7 个研究 人员, 2 个工友, 一共 9 人, 并把地理所改称中国科学院地理研究所筹备处, 由副院长竺可桢先生兼任筹 备处主任. 直到 1958 年, 中国科学院地理研究所才从南京迁到北京, 在南京留下以周立三先生为首的一 个班子, 包括在座的余之祥先生、沈道齐先生等几位, 还设立了以华东水利学院(河海大学前身)教授施成 熙先生兼主任的湖泊研究室. 我在 1953 年就离开了南京, 直到 1985 年又重返南京地理所. 那时候, 我从 兰州冰川所所长的位置上下来，任名誉所长，我又不甘心老死在兰州，于是通过科学院人事局跟江苏省 联系, 到这里来当兼职的研究员, 这边又给我安排了住房, 此后我就像候鸟一样, 夏天在兰州, 冬天到南 
京，一年当中，居住时间在南京多一点，工作任务在兰州多一点. 自从退下来到今天，我身体的健康状况 一直还好, 研究工作一直没有中断. 我回到南京来, 第一个要感谢的是屠清瑛所长, 屠所长解决了我的 房子问题, 解决了我女儿、女婿的工作问题. 我到所里以后, 开展的第一项工作是关于气候和海平面变化 的研究项目, 这个项目是国家自然科学基金委委托南京地理所领头, 由我来主持的. 当时这项工作的主 要参加者有朱季文、季子修等多人, 季子修最早在兰州就跟我合作, 我们一起在希夏邦马搞冰塔林的考 察研究, 研究冰塔林是如何形成的. 到南京来我们又在一起搞海岸带的研究项目, 当时杨桂山也参加了, 还有王洪道、秦伯强、范建华, 参加西北气候与水文项目. 和王苏民等一起搞全新世大暖期的研究, 此前 还开展了青海湖研究的工作, 那时候他起到很大的作用, 全新世大暖期的那个等温线就是他画出来的. 在这之后, 又开始一起搞青藏高原, 这项工作吴敬禄也参加了. 回顾历史, 我做的每一件事情, 取得一些 成绩, 都离不开大家的帮助. 还有李世杰, 也给了我许多帮助. 后面几年就开始搞长江的研究项目, 项目 负责人是姜昨, 在座的不少研究生, 包括张强、苏布达等很多人, 都参与了. 应该说, 1985 年以后以我的名 义发表的文章, 我没有做过准确统计, 但可以肯定, 在数量上不少于 1985 年以前; 当然从原始创新的意义 上来说, 我后来做的工作可能不如以前, 因为受到体力的限制, 再上冰川已不大可能了.

今天我还要感谢南京很多同志的帮助. 在座的余之祥同志, 他主持长江分会的工作, 我们一起到贵 州考察、开会; 还有王富葆同志，他写第四纪冰川方面的文章比我还要早，当时他和刘振中、刘泽纯在 1962 年的地理学报上发表过一篇关于珠穆朗玛峰、腾格里峰、祁连山团结峰附近第四纪冰川的文章; 还 有古生物所的唐领余同志长期参加第四纪气候变化的研究工作. 因此我说首先要感谢大家对我的帮助, 包括刚才提到名字的，也包括没有提到名字的，我取得的成绩，都是在大家共同努力下才能取得的.

在我 80 岁的时候大家为我祝了寿, 当时我说, 到 90 岁时就不要再做了. 等到 90 岁的时候, 却还是有很 多方面提出要为我祝寿. 上一周的 16 号, 在江苏的浙大同学会为我举办了祝寿活动, 浙大的常务副校长特 地从杭州赶到南京来参加, 他给我带来了很多礼物, 其中有一件是我大学本科时期的成绩单, 我以前从来 没有见到过, 还有一份是我考进浙大的人学考试成绩单. 我的一生值得庆幸的是上了一个好大学, 浙江大 学, 当时浙江大学的校长竺可桢, 是一个了不起的人物. 如果要论说 20 世纪中国教育史上的地位, 恐怕除 了蔡元培, 其次就是竺可桢了; 但是要说当校长的辛苦程度, 蔡元培就远远不如竺可桢了. 竺可桢当浙江大 学的校长, 恰好是在抗日战争期间, 竺可桢带领浙大师生西迁, 在非常艰难的条件下教书育人, 还坚持做科 学研究工作, 英国著名科学史家李约瑟来到浙大的西迁地一一贵州遵义涺潭实地参观考察, 对当时的浙大 就有“东方剑桥”的赞誉. 当时浙大汇集了许多国内第一流的好老师, 譬如我的导师叶良辅先生, 是一位著 名的地质学家, 还有涂长望, 著名的气象学家, 解放后首任国家气象局局长, 南大任美锷先生当时也是我的 老师. 浙大史地系的地学专业创办于 1936 年, 一直到抗战结束, 当时在校学生不多, 也就是一二百人, 这一 阶段浙大史地系为国家培养了许多地学人才, 师生中有 10 人后来成为中国科学院的院士. 浙大有很好的校 风, 学生关心时政, 追求进步, 蔚然成风. 在这期间, 我结识了几位很好的同学, 其中一个就是吕东明, 他 早在 1938 年就人党了, 后来他成为我参加革命的领路人与人党介绍人. 我人党是在 1947 年到南京之后, 当 时组织上要我做情报工作, 收集军事情报, 当时我心想自己身在研究所, 哪能搞到军事情报呢. 后来还是设 法找到了几个可靠的联络人, 其中一个在下关车站做事, 要他专门收集国民党军车调动方向的情报, 有一 个在金陵兵工厂, 还有一个在下关电厂, 都是在要害部门工作, 通过他们得到了不少有价值的情报. 1949 年 4 月 20 日, 国共和谈破裂, 李宗仁不愿意在协议上签字, 当天晚上解放军就开始从几路过长江，形成包围 南京的形势, 4 月 22 日国民党军队就撤退了, 4 月 23 日晚, 解放军就占领了南京.

解放以后, 百废待兴, 我参与了地理界创办 《地理知识》杂志的工作, 当时推举李旭旦先生领头, 在 地理所有周立三先生、吴传钧先生、高泳源先生和我四个人, 南京大学有李旭旦先生、杨韧章、胡豁咸, 还有王煦柽先生，一共八个人. 我们第一次办杂志，没有经费，大家自己掏钱，出第一期，印刷纸张很差， 八个页面, 一共印 600 份, 受到广大读者特别是中学老师的普遍欢迎. 上海一家私营的亚光與地学社来 信跟我们联系, 约定这份杂志今后由我们继续编辑, 由他们负责印刷、发行, 还可以为作者提供稿费. 就 这样我们把这个杂志办了起来, 后来发行得很广, 办得很兴旺. 到今天, 这个杂志已经改名为《中国国家 地理》, 杂志社的负责人叫李栓科, 是北师大毕业的, 这个人很有气隗, 把改版后的国家地理杂志办得有 声有色，现在发行量已经是上百万份，还发行了繁体中文版、日文版、英文版等多种外文版，成为改革开 放后办得最有创新特色的一份杂志. 解放后我在南京待了两年, 又去北京工作几年, 后来又去兰州搞冰 川冻土研究, 工作条件要艰苦一点. 我为什么会去搞冰川研究呢? 说来话长. 那是 1957 年, 我们到祁连 山西段考察, 在党河南山的北坡看到远处有一座雪山, 有冰川, 好像路不很远, 第二天我和郑本兴、唐邦 
兴等几个就跑过去了, 起初我们都没有经验, 以为当天可以来回, 哪知道在西北是“望山走死马”, 走了整 整一天, 才走到山脚下, 看天色已晚, 不能上山了, 只有第二天再上山. 上山以后, 一直上到 4500 米, 看 看手表已经是下午 5 点钟, 实际上是当地时间 3 点钟. 我们在冰川上面转了转, 摸了点雪吃吃, 这一回我 们对冰川算是初次认识. 从冰川上下来, 见到山下水草丰盛, 牛羊成群, 还有不少蒙古族牧民的帐篷, 这 是在山的北坡; 几天之后, 我们又绕到山的南坡, 在那里见到的却是另一番景象, 南坡非常干旱, 冰川也 没有, 走了半天都找不到一口水喝, 和北坡形成鲜明的对比. 通过这一次考察，我们切身体会到冰川融 水在西北水资源开发中的重要性, 在我们回北京之后, 就打报告要求组织专门的冰川考察队, 科学院批 准了我们的报告, 冰川考察队很快组织起来, 还请了苏联专家, 这样, 从 1958 年起我们就开展了祁连山 冰川的全面考察. 我们国家的冰川研究事业也就是这样从无到有, 逐步发展起来的.

今天我要讲的是, 第一, 我的成长离不开许多老师、同学和朋友的帮助, 我要感谢大家对我的帮助, 我取得的成绩, 首先是依靠大家帮助. 领导好也有很大的关系, 如果碰不到贤明的领导, 你是出不来的. 我这一生遇到了很多好的领导, 竺可桢, 是我的大学校长, 后来当了副院长, 还有当时科学院的党组书 记张劲夫、裴丽生, 他们对我们的工作都是非常支持的. 1959 年, 在全国开展反彭德怀的反右倾运动, 各 个地方都抓右倾机会主义分子, 那时候我到了北京, 在科学院一起开会学习, 参加运动, 结果把我也批 倒了, 把我批了三个月. 后来张劲夫给我下结论, 说施雅风思想错误是严重的, 但工作还努力, 所以不给 处分. 很显然, 张劲夫是有意识地要保护我, 他还保护了其他许多人. 当时地理界的罗开富就当了右派. 到文化大革命, 更是一言难尽. 后来到 1978 年, 着手编竺可桢文集, 我们到竺老家里向竺师母搜集相关 的材料, 竺师母说, 老头子有一批日记, 1936 年以后的, 都保存好的, 装在床底下的箱子里, 这些日记在 竺老生前是不让家里人看的. 在我读到这些日记以后, 感到即使在最艰难的日子里, 竺老的思想境界一 直是积极向上的，这就打消了我在文化革命时产生的一些消极思想. 后来一路一路走过来，我觉得很庆 幸, 碰到许多真正认识我的人. 记得我在当选学部委员时, 黄秉维先生告诉我, 当时有三个人参加评审, 包括黄秉维先生、黄汲清先生, 还有程裕淇先生, 地理方面的候选人都由他们三个人审查, 如果他们三人 都认可, 就可以通过了, 我就是在他们三位手下评审通过的.

大家为我祝寿, 我的话已经讲多了. 我对地理所今后的发展寄予期望. 现在所里有 100 多个编制, 加 上研究生, 人已相当多了. 现在是人才不少, 要比我们当年办研究所的时候强得多得多, 但人才怎么更 好地组织安排, 团结合作, 把研究所的地理、湖泊两方面都搞上去, 我觉得目前湖泊方面比较强, 地理方 面有些遗澸, 地理还不够强, 地理方面还有许多工作要做, 要开辟, 要努力, 不要限于原来的工作, 完全 有条件开辟, 开辟不一定要人多. 今天杨桂山所长在这里, 希望能够努力把地理所搞上去, 要有高水平, 真正要办成一流的研究所, 就像古生物所那样, 出一流的成果, 培养一流的人才.

屠清瑛: 我一生中尊敬的老前辈很多, 施先生和周所长是我一生中最尊敬的前拝, 为什么呢? 因为治学、 为人都是我们的楷模, 我觉得施先生一生孜孜不倦的这种治学精神造就了我们国家地学和冰川学的顶 峰，施先生的为人非常平易近人，对我们后拝的教育一直是诲人不倦的，施先生对我们所帮助非常大, 施先生来了以后, 一直关注我们所的业务、方向, 关心我们所学科的建设, 关心我们所的人才培养, 对 《湖泊科学》杂志的质量提高, 施先生都是付出了很大的心血.

李世杰: 我先代表分院恭贺施先生 90 华诞. 我给施先生写了副对联, 大家给提提意见. 上联: 勤奋求实, 一代宗师, 桃李遍天下; 下联: 开拓创新, 时代相传, 硕果丰民生. 借此机会, 我先谈谈跟施先生这么多 年的体会和感受. 我是南京大学毕业的, 在座的王老师、朱老师都是我老师. 我大学毕业以后, 1982 年 9 月份研究生人学, 此后一直跟着施先生. 1994 年 4 月施先生到了兰州, 告诉我他要在兰州带一个星期, 可 以把专业课先考了. 考试就我一个人, 一个人监考, 施先生给我出了 3 道大题(每道题都可以做个博士论 文), 科研处处长监考, 给我 3 个小时, 答了 12 页. 施先生很满意. 接着考英语, 英语考完我们就到西昆仑 山去考察了 3 个月, 8 月底我还在野外, 所里有人通知我被录取了, 从此以后, 施先生言传身教, 受益匪浅. 中间还有一次出国机会, 施先生亲自帮我联系英国教授去做合作培养的博士. 当时我去那里呆了一年, 施老不断给我写信, 回来以后一直做青藏高原的研究. 要求我们工作要做的非常扎实.

赵其国: 记得认识施老的时候大概是 30 年以前, 当时竺可桢奖学金的主持人是施老，我记得是你给我发 的奖状; 大概是 1984 年, 那时候我还没有做所长, 施老是主任委员, 我觉得施老很不简单, 发的奖是野 外工作奖, 当时我对施老就是怀着比较崇敬的心情, 后来我做了所长前后, 在科学院里面参加了一些工 
作会. 我和屠清瑛经常碰到施老, 施老那时还没有到这个院子里来. 我觉得施老在地学界是一个有非常 有造诣的、思想比较开阔, 有创新思路的、一谈起话来基本上都是在战略思路的, 非常受启发. 后来接触 的是我做所长不久后长江流域的考察, 我没有具体参加. 施老是亲自参加的, 能身体力行, 对三峡库区 生态环境提出问题, 我觉得施老在科学院地学界是一个很值得崇敬, 使人身临其境的、重要的能够带动 大家共同工作的老先生. 施老的革命激情值得敬佩, 但是施老的奉献精神和道德情操更需要一代代传承, 传得好，事业发达; 传得不好，事业就不会兴旺.

王 颖: 施先生给我记忆最深刻的, 是又红又专. 说实话, 我始终没有体会红的重要, 刘(东生)先生也是 又红又专的. 施老知道如何团结人，培养人，像李吉钧、秦大河、程国栋、姚檀栋院士. 施老思想开阔，境 界更高，知道如何建立自己的梯队; 而且，施老对老师非常尊敬，比方对竺可桢先生; 施老通过编辑出版 《竺可桢日记》, 继承了笔先生的精神和情操. 现在 90 高龄思维如此清晰, 思想敏锐, 是因为施老不断 学习, 跟科学发展前进. 施老淡泊名利, 宽以待人, 这就是长寿的秘诀. 我非常尊敬施先生, 我祝施先生 还有沈先生健康美满幸福, 领导着我们从事地学探索一直到 2020 年吧.

徐 琪: 我没有福气做施老的学生, 在三峡工程生态环境影响的论证过程当中, 受到施老的启发教育, 尤其是海 平面上升对下游的影响, 这作为一个大问题, 现在也不断的得到证实, 所以在这一点上, 我是非常感谢施先生.

王富荣: 施先生给我最大的印象就是无私奉献、淡泊名利. 那时在兰州, 施先生组织写了一本珠穆朗玛峰地 区的考察报告，1975 年出版，在出版的前言里边，用了毛主席的语录“不断创新，不断前进”，施先生就一直 是这个样, 不断创新, 不断前进, 无私奉献. 大家都知道, 现在我们国家的青藏高原研究取得了很大的成绩, 在国际上很有地位, 但是青藏高原研究开始的发起人, 可能大家还不知道是谁, 实际上是施先生和刘东生 先生. 施先生和我们这几个人在兰州搞完了珠穆朗玛峰地区的科学总结以后, 施先生就马上提出来, 我们 继续要搞西藏, 要搞青藏高原; 就把刘先生请到兰州, 研究计划, 报科学院, 从那时开始就同意青藏高原中 国科学考察队，从此进行了几个阶段的青藏高原考察，这个考察取得了很大的成果. 我自己和施先生一起 工作的过程中, 我的感触就是, 施先生不断的创新, 不断地贡献, 而且淡泊名利.

唐领余: 我不是地理学家, 但我从 1963 年南大毕业开始, 就跟着施老从事青藏高原第四纪孢粉研究已四十 多年. 最初施先生亲自指导我如何将孢粉分析在地理学上应用, 派我去兰州地质所、北京地理所、植物所跟 专家学习; 让我参加蓝田、木里煤田、西藏冰川冻土等综合科学考察. 使我一个植物专业的学生, 学到了第 四纪野外方法. 最初开始研究是青藏公路沿线第四纪地质环境. 施先生让我们抓住昆仑山垭口剖面和楚玛 尔河深钻, 建立典型剖面, 并在我文章后提出云杉花粉在解释第四纪环境中的重要性, 给狍粉研究指示了 一个关键学术问题. “85” 期间, 我参加施先生的重大课题 “中国气候与海面变化及其趋势和影响的初步研 究”, 指示我们在长江中下地区全新世孢粉研究时, 不能停留在定性上, 要尽可能的定量半定量建立标准剖 面. 施先生经常让我去他办公室, 指导我如何抓住关键问题深人研究, 经过几年的努力, 我和我的学生终于 树起了(苏北)庆丰剖面, 在《中国科学》上发表. 这是我国最早应用转换函数定量恢复古气候的狍粉研究. 在 大课题总结时, 施先生让我们住在香山一个星期, 集中精力写出 “中国全新世大暖期气候与环境” 初稿. 后 来施先生在国内外出版和发表多部专著和论文，使我学到搞研究要抓总结、出成果。“95”期间，施老又全 力组织全国各专业科学家进行 “青藏高原晚新时代隆升与环境变化” 研究. 施老特别重视植被演替的重要 性, 亲自组织孢粉古植物学者出谋划策, 让我召集近 20 位狍粉学者做学术报告, 出版专刊, 专论青藏高原 中新世以来植被演变. 最终在他的专著中用 20 余页图文并茂地叙述了青藏高原中新世以来植被与环境. 使 这一地质时期高原植被演替有了初步概貌. 在他多年指导下，我也迷恋上青藏高原第四纪研究，一直坚持 了 40 余年. 近几年来, 我和他的学生正在研究冰心孢粉记录的青藏高原的 2000 年来气候与环境变化以及我 国西部干旱半干旱地区全新世植被演变与环境变化, 仍与他的指导分不开. 跟随施老几十年, 使我逐渐成 长、成熟, 不仅是学到全身心的投人到研究工作的钻劲, 还学到了如何做人的品德. 当我们在藏区高原考察 几个月没有蔬菜时, 他从西宁买水果罐头送上山; 在我高山反应严重时, 他用车带我下山; 得知我家中孩子 生病, 他借钱给我; 他的学生在野外没有换洗衣服, 他在拉萨给买一套西装; 他被关在牛棚时, 在则所遇到 我还偷偷问我西藏考察有什么收获……非常感谢施先生多年来对我的培养、教育和指导.

朱 诚: 我的三位老师算是施先生的学生. 我应该算是徒孙. 1984 年, 我考取中科院兰州冰川所研究生后, 施先生给我们上的第一次课就是讲科研道德，让我看到了施先生对研究人员即关心又爱护又严格要求的 
那种作风. 1985-1990 年, 施先生当时已经是 60 多岁了, 但是仍然不畏高寒缺氧的艰苦条件, 每年都到冰 川站上考察、检查工作; 甚至一年中要多次上冰川站, 施先生在这方面是身先示卒, 以身作则, 注重实践, 严谨求是，这种作风使我们深受鼓舞. 1993 年，我的第一本著作冰川冻土地貌，请施先生给我写个序，施 先生是欣然应允, 让我非常感动. 施先生非常平易近人, 我每年年底会给几个主要的老先生寄贺卡, 但 是施先生每年都会给我回一个贺卡, 贺卡里面还把这一年他做的什么工作打印出, 还要附上一张照片, 写了几本专著, 我真的受感动. 再一个就是施先生工作的效率非常高, 主要体现在做每一件事上都善于 总结, 带研究生出野外, 回来规定每一个研究生都要写一个总结报告, 这对研究生素养的提高非常重要. 另外一个就是施先生在中国东部第四纪冰川问题上表现的“吾爱吾师，吾更爱真理”的求真务实的精神更 是应该奉为我们做科学研究的准则. 施先生不愧为我们人生和学术道路上的良师和楷模.

张忍顺: 我是搞海洋的, 施先生长者、学者的风范给我留下深刻的印象. 当我在研究江苏海岸的时候, 我 向施先生请教, 施先生对我的研究计划都给出了非常具体的指导, 我还多次邀请施先生对我的课题进行 当面指导, 参加我项目的鉴定会, 施先生每次去的时候对我的帮助都非常大. 对施先生在学术方面的成 就和他的为人, 大家有目共睹. 在学术上我还没资格评价施先生的伟大的贡献, 但是对施先生的为人我 感觉特别深. 施先生广博的知识, 广泛的兴趣给我留下很深的印象. 施先生还经常跟我谈起他的以前的 一些经历，如如何从南通来南京要走三四天的时间，在苏北的小运河里坐小船等等，我觉得很受感触. 虽然我没有这个幸运成为施先生的学生, 但是施先生的言谈话语, 言传身教给我留下了非常深刻的印象. 所以施先生对科学的奉献精神和为人处事的方式都是我学习的榜样. 另一方面施老对年轻的一代也是很 关心, 我的一些研究生也经常向施先生请教.

王苏民: 我在施先生的指导下进行工作的时间还是比较长的，1963 年在南京召开的全国地貌会就是讨论 任先生的金沙江结构，当时地貌界的巨头都在. 当时施先生也来了，还到南大给我们作了一次学术报告， 这是首次认识施先生. 深人接触的时间是在 1986 年, 在施先生直接领导下开展中俄合作的青海湖研究. 在我和施先生这么多年的接触当中，他有这么高的成就，有几点是很突出的：第一，就是树人，对培养人 方面施先生做的是非常好，施先生对工作是那么的细致，并且每时每刻都在考虑工作. 施先生对博士进 行不遗余力的指导, 我这里不举太多的例子. 对现在很有名气的科学家姚檀栋的培养我也或多或少的经 历一些, 当时他刚从法国拿了博士回来, 施先生在指导他做冻冰芯的过程里面, 施先生带着他去找叶连 俊先生, 就冰芯问题跟叶先生讨论. 施先生对科学家的培养是付出了心血. 第二, 施先生在科研上的敏 感性, 这点是我一辈子也学不到的. 在科研上如何敏感, 能够抓住一些问题. 好比说施先生在三阶段上 不断提出了自己的看法, 形成了一种学术观点. 再一个就是关于青藏高原隆起的问题, 我认为施先生就 是很敏感, 因为青藏高原后期的研究已经对原来传统的观点提出了挑战. 再也不是说全新世那时候才 1000 米, 施先生认为那不对, 现在愈来愈多的资料表明大季风的发育要早的多, 施先生第一个发表了两 千万年、两千二百万年的时候季风就开始发育了, 某种程度上和老的观点不一样. 同样是一起工作的科 学家，就没有这个敏感性. 再比如在秦大河组织写西部那本书的时候，施老是顾问，他马上就能抓住新 疆气候为什么会暖会湿这个问题，提出了气候转型的问题. 这些都表明了施先生在科学研究问题上高度 的敏感性，因为他渊博的知识能够抓住现象的要害，效果非常好. 第三，施先生在抓工作当中雷厉风行， 一丝不苟，以身作则，身教言教. 在进行青海湖研究的时候施先生已经七十多岁，每天晚上三点钟起来 看书，从三点钟看到五点钟. 他带的行李里面总是有很多外文书籍，看到好的了就说王苏民你也拿去看， 他以身作则, 做事情一丝不苟. 在湖泊专项、冰冻学专项和山地灾害专项里头, 施先生是冰冻学专项的首 席科学家. 他那个时候是三大事情融合在一起，一个是青藏高原 973 的问题，分工分的焦头烂额; 一个是 专项的问题; 还有一个重点基金的问题，那个重点基金是比较大的重点基金，不是一般的，也是青藏高 原的重点基金. 三个事情搅在一起, 施先生已经累垮了, 讲话声音都没有, 下楼梯走不动, 扶着楼梯走路. 程国栋拿着冰冻圈的申请书给施老审查. 施先生说你放这儿吧, 我瞅个时间慢慢看. 当时我特别受感动, 一个老先生已经病倒了发高烧，嗓子全部哑，下面的人把东西送来施先生没有回绝. 施先生做的是言教 身教, 由于他的榜样的作用, 我们也得好好干. 这么多年我从施先生那里学到了, 一个优秀的科学知识 分子，一个老科学家的优秀的品质. 这些东西都值得我一辈子加以学习, 我自己感觉到差距非常大.

会之祥: 在这里我算认识施先生比较早的一个, 因为在 1956 年施先生陪着俄罗斯专家到新疆去考察, 那时 候我们刚好在新疆考察队, 施先生也不过四十岁, 正风华正茂, 而且在科学学术活动上那时候就看出施先 
生的前沿和活跃的能力. 我虽然没有在施先生的直接领导下做工作, 但是我有个区位优势, 因为施先生来 南京后住在我的楼底下, 所以我经常会利用这个区位优势去向施先生请教很多问题, 这里面给了我许多体 会. 这里我只想讲两三点具体的事情, 施先生不仅在地理学冰川研究方面很建树, 其实在三峡考察里面, 他 最早在 40 年代就做了三峡的调查研究. 而且他在三峡工程提出很好的见解来指导这项工作. 同时, 施先生 他也涉及了地理科学方面的发展, 前两三年我在施先生家里面我就谈了我们地理学在解放后在农业地理上 做了大量的工作，而最近这些年有边缘化的迹象. 施先生就这一点一定要我写一个东西，而且施先生自己 签名让我到北京请地理界的吴传钧先生还有陆大道先生, 还有地理学会专门给科学院方面写信, 起到作用 最简单就是在北京地理所首先建立了农业地理农业农村研究中心. 可惜在我们南京地理所没有起作用. 刚才我跟杨桂山同志讲, 这个问题很值得注意. 我们地理学在农业农村建设社会主义新农村有大量的研究 问题, 但这个我们所已经萎缩了, 值得我们重视. 我还有一个体会就是一个大科学家他能够站在一个高度 上不仅能够对自己门类注意，同时能够在各个方面都能看到他的发展，这点我有很深的体会. 做任何事情 不要只顾及到自己这一点点, 同时也要看到旁边的. 因为我觉得地理学所有做出成就的人都是有很多方面 的支持起作用. 一个个人也不可能做出太大的成绩, 但是施先生能够团结那么多人, 能够把自己团队建设 的那么好，同时又能看到地理界其他方面的发展，我觉得地理界有这样的老先生是非常荣幸的.

朱大奎: 我跟施先生认识也是很长的, 正式见面是改革开放以后. 但是我们 1952 到 1956 年在南大上学的 时候, 就知道施先生, 因为我们的老师杨怀仁先生, 我跟杨先生很多很多年了. 杨先生一直讲浙大的事 情, 讲施老. 特别是施老在我们老师那里是一个又红又专的人. 真正见到施先生时候是在北京平谷县开 地理学基础科学一个会议, 具体您讲什么记不得, 但是感觉您对地理学的问题看得比较远. 施先生出了几 本科普书, 关于冰川的书, 还有一本自传类的书, 我都看了, 感到有很广博的地理学知识, 也有自己深人 的关于冰川气候变化等的知识, 有气候变化、环境变化的内容, 我总是想, 气候变化、环境变化的概念是 在 80 年代之后才有的, 施先生那时候就提出了, 为什么能够做得那么深? 是因为有坚实广博的地理学的 知识, 可以促进不断的深人. 两点对我启发很多, 第一不能讲老, 要不断拼命向前, 第二不要觉得自己知 识不够, 只要我们有一定基础知识后需要什么学什么, 可以不断学习向前.

王 建: 施先生对我们这些年青人来说有点敬畏, 但是和施先生接触后感觉到平易近人, 从 80 年代后期, 接触相对多一些, 对我来说感觉收获比较大的有: 第一, 施先生跑野外比较多, 无论年纪多大, 常常跑野 外, 海洋、冰川、南极等, 对我们年青人收益多, 我们要把地学的东西搞好, 要跑野外, 包括我第一个自 然基金, 在若尔盖草原上设沉降板、现在青藏高原面上项目, 我也去青藏高原 4-5 次了, 就是受施先生脚 踏实地的做野外工作的激励, 第二, 尽管施先生科研做得比较好, 但是也重视地理教育, 有几次我们请 施先生给我们中学地理老师培训班和研究生讲座, 施先生用亲身体会告诉中学地理多么重要, 他就是在 中学听了地理老师的课, 才选择了地理, 走到现在. 从那时候开始我也受到启发, 大学特别师范大学, 我 也开始重视地理教育, 后来开始编写了 21 世纪教材、后来的中学地理教材等, 每年几十万人次的使用. 第三是施先生宽大的胸怀、平易近人的人格，在感染着我，包括我以前在地理学院，现在在校长的管理岗 位上都受到施先生胸怀、平易近人的人格魅力的感染.

杨达源：施雅风老师是地理环境的创导者, 是我们的领路人, 是我们进行地理环境研究的靠山, 施老师关 于长江三峡砾岩的研究使我明白大江深处沉积物的特性和其古地理意义, 第二是关于大暖期延续到距今 3000 年的研究, 为距今 3000 年为限的古洪水的研究奠定了基础. 第三是积极热情的支持我们在三峡、金沙 江研究, 我们在金沙江边找到了非金沙江的阶地, 以及阶地堆积物的年龄是百万年左右, 对目前全球变暖 的研究我们似乎也找到了地理工作者应做的事情, 变暖原本是气象的记录, 而我们地理工作者特别关注全 球变暖的区域响应和全球变暖的环境效应. 前者本为全球各地地理的差别, 后者包括全球变暖对各地产生 不同的实际效果, 例如我们对苏南地区是全球变暖导致季风环流导致的不稳定的研究, 施老师您的指导使 我们对地理环境的研究充满了希望, 也充满了期待, 也把我们带上科学研究的道路, 天天向上.

秦伯强: 我们的学生有许多是施老培养的, 施老在南京培养的学生, 我可能是最早的一个, 1987 年我跟施 老的博士, 1987 年后去新疆，参加王洪道先生主持的乌伦古河的项目，同时参加王苏民老师的项目，那时 我们在考察的时候找不到路了, 到处找, 大家担心施先生的身体, 王苏民老师让我们换着您走, 您不让 换. 1988 年您从南极回来, 我去拜访您, 送我南极首日封和企鹅毛. 您告诉我每次出野外都要做笔记, 每 年发 2-3 篇文章, 要求我们对我们很有帮助, 施先生对我个人成长帮助大, 且对我个人人格完善很重要, 
潜移默化影响. 您常常对我们说要多看别人优点, 不要仅看缺点. 您教育我们知足常乐, 助人为乐, 自得 其乐, 三个乐教育我们, 这种人生感悟对我们有很大影响, 感受很深.

姜 䑣: 我们课题组近来协助施老编写《地理环境与冰川研究》的续集, 施老总结多年工作, 其中长江的 研究, 他写了全球变暖对长江洪水影响的研究, 2002 年,施老一直在南京推动工作, 比如长江洪水的研 究、气候变化的研究，都和施老的推动有关系. 在施老 90 年华诞的时候，课题组送施老一幅字“长江情”.

朱季文: 我在施老师指导下工作是 1985 年之后, 但是就我而言, 1962 年工作的时候就听到施老的介绍, 1985 年后在他指导下工作, 感受很深, 受到教育. 当时一个项目开始研究, 有 200 多人, 组织难度很大, 1988 年开始设计, 当时施先生已经近 70 岁, 工作量大, 施先生检查工作, 不仅仅开会, 而且直接布置工 作课题, 抓得很紧. 施先生在 30 年前就将气候、冰川和海平面联系在一起, 而且在兰州南京都找资料文 献写信给我，还亲自送到我办公室，当时我感动得不知说什么好. 施先生重视实践，抓第一手资料，1988 年提出要实地考察，从连云港到上海等地考察，对项目指导，特别是对海平面课题的指导很有力，对沿 海地区的经济建设有很重要价值. 另对我本人、课题组成员要求严格, 为了成果我也挨过批评, 的确后来 振作起来, 不能因为我拖项目后腿, 让施先生着急, 后来完成了项目, 项目获奖还给我一个证书.

季子修: 施先生的贡献在学术很大是现代冰川科学的奠基人, 1958 年之前也有如李四光先生庐山的冰川 工作, 1958 年施先生带人去祁连山考察, 冰川学开始发展, 做冰川工作需要很大勇气, 比现在搞湖泊困难 多. 施先生对冰川的研究, 思维超前, 包括对于庐山的冰川, 尤其沉积物的资料、狍粉沉积等揭示庐山有 冰川证据不足. 施先生研究问题考虑有充实的证据. 同时与时俱进, 80 年代看到气候变化、环境问题, 施 先生开始了这些问题的考虑. 除了重视理论问题的探讨外，也重视生产问题，如祁连山融冰化雪问题、海 平面上升问题，对于沿海地区经济发展影响问题，对于海堤加高等的研究等，受到很大重视，去年国家 海洋局编写了长三角海域环境规划纲要, 把施老的文章全文收录在规划中. 施老的研究成果在学术上、 生产上、学科建设上都起到很大作用.

陈家其: 我很荣幸参加这个会议, 1958 年我就听说过施老, 我当时的老师就在施老的领导下参加祁连山 考察, 当时对施老很仰慕, 但很遗憾到 1985 年之后才得到施老的亲自指导. 这次很荣幸, 拜读了施老 4 卷的文卷，感受很深，施老在这里面写了以前的论文还有许多小的短文，还有对过去的回忆等等. 这不 仅是施老的文献，而且是科学发展史，一个学科的发展史，一个单位如何发展起来的，资料如何积累起 来的, 看了后受到很大教育. 读后感到施老有这么强的学术能力、组织能力, 指挥能力不可多得, 作为科 学工作者要有奉献精神, 德才兼备, 德要为公, 坚持真理, 及时修正错误, 施老正是这样做的. 感到施老 有这么强的学术能力、组织能力，归到底是施老的品德魅力!

李万春: 《湖泊科学》杂志 1992 年创刊, 施老出任第 $1 、 2 、 3$ 届编辑委员会主任, 为《湖泊科学》的发展 做出了极大贡献. 他高瞻远瞩, 引导《湖泊科学》关注譬如全球变化的湖泊响应、湖泊富营养化发生机制等 若干热点领域. 对于争论性文章，有些评审没有通过，争论多，不知是不是可以发，请示施老，施老鼓励发， 说只要大家敢写, 敢署名, 就可以发, 文责自负, 后来证明发的许多文章很有价值. 在办刊理念方面, 施老 要求解放思想, 进一步拓宽思路, 积极探索, 加强对湖泊环境、生态系统退化诸多问题发生过程与机制, 以 及生态学和地理学等基础理论领域的报道力度，贯彻以报道基础和应用基础研究成果为主，同时及时反映 湖泊治理和环境保护等管理、实践领域的需求和实证研究成果. 《湖泊科学》目前已经成长为国内湖泊科 学领域最权威的学术期刊, 其学术影响力不断扩大, 根据中国科学引文数据库的统计, 2000 年至今《湖泊科 学》的影响因子一直位居全国前 100 名, 这是与施老多年的努力和引导分不开的. 另外, 施老学术态度很严 谨, 上次 80 大寿出版的《地理环境与冰川研究》的文集里面所有的文章都是重新审阅、修改后才发表的.

杨桂山：下午时间宝贵，许多同志都想发表讲话，但是没有时间了，刚才许多前辈、施老的学生弟子在一 起畅谈了和施老在一起工作学习生活的情景. 对施老又红又专、淡薄名利、尊老携幼、无私奉献、对施 老发展学科、重视野外、对施老一生追求科学等谈了许多. 我 1988 年来所工作, 1993 年跟施老读博士, 学 问学得不够, 但是施老的为人一直影响自己. 值施老 90 华诞之际, 送施老一幅字“厚德载物”, 该字为徐悲 鸿的儿子徐庆平教授所书, 我们晚辈一起来送给施老. 我们不但要学习施老对科学不解追求的精神, 更要 学习施老厚德载物的高尚品德. 可以说施老取得的成绩和施老的品德是密不可分的!

(据录音整理, 有删减; 部分发言未经当事人审阅.) 